http://jmscr.igmpublication.org/home/

ISSN (e)-2347-176x ISSN (p) 2455-0450

crossref DOI: https://dx.doi.org/10.18535/jmscr/v7i8.115

Journal Of Medical Science And Clinical Research

\title{
A Study to Assess the Level of Stress among Women Undergoing IVF Treatment in Art Centre of a tertiary Care Hospital
}

\author{
Authors \\ Lt Col Sindhumol P K $\mathbf{1}^{1}$, Lt Col Sreeja K $\mathbf{K}^{2}$, Maj Beena S Babu', \\ Maj Pooja ${ }^{4}$, Maj Sangeeta Yadav ${ }^{5}$ \\ ${ }^{1}$ Tutor, CON Pune, ${ }^{2,3,4,5}$ Student, CON Pune
}

\begin{abstract}
Infertility is a life crisis affecting couples all around the world. Infertile couple all around the world experience a tremendous amount of emotional turmoil. The risk of depression, anxiety and stress is high for infertile patients. With the objective to assess the stress level among primary infertile women undergoing IVF treatment and to determine the association of stress level with sociodemographic variable. This study was conducted in the Assisted Reproductive Treatment centre of a tertiary care hospital. Nonprobability purposive sampling technique was adopted for selecting subjects for the study. Quantitative approach, nonexperimental descriptive research design was used for the study. Newtons Fertility inventory, modified state anxiety score was used to assess the stress level. The study findings reveals that only $1.7 \%$ of the subjects had high level of stress related to treatment outcome. Majority of subjects $51.6 \%$ experience only mild level of stress, 30\% subjects had almost negligible stress and $16.7 \%$ had moderate level of stress.

Keywords: primary infertility, stress.
\end{abstract}

\section{Introduction}

For women pregnancy and motherhood are developmental milestones, highly emphasized by our culture. Infertility is a life crisis affecting couples all over the globe contributing to high level of anxiety and distress and increasing the risk of depression. Infertile couples experience a tremendous amount of emotional turmoil. Failure to conceive can be an emotionally devastating experience. Therefore it is important for the health care professional to understand the psychological issue experienced by infertile couples.

\section{Background of Study}

The world health organization (WHO) estimates that 60 to 80 million couples worldwide currently suffer from infertility. Prevalence rates showed that 40 to $55 \%$ of infertility is primarily attributing to females.

Approximately $75 \%$ of couples diagnosed with infertility will seek medical treatment. The procedure of diagnosis and treatment of infertility is time consuming, economically and psychologically burdening the couples, without guaranting.

Pregnancy It has been hypothesised since biblical times that stress can hamper fertility and it is definitive that infertility treatment leads to 
significant distress. Moreover, the investigators personal interaction with the couples affirmed the same.

\section{Method}

A descriptive study was conducted on 60 subjects undergoing IVF treatment for primary infertility in the selected tertiary care centre selected by non probability purposive sampling technique. Non experimental quantitative research approach was adopted. Newton's fertility index and modified state trait anxiety scale were used to assess the level of stress and anxiety among women undergoing treatment.

\section{Result}

Analysis done with by inferential statistics. Majority (55\%) of the subjects belonged to age group of 26-30 years and (87\%) of them were homemakers. Majority , $51.6 \%$ of the subjects under the study experience only mild level of stress,30\% of subjects are having almost negligible stress, $16.7 \%$ have moderate level of stress and only $1.7 \%$ is had severe stress related to treatment.
Table 4.1: Socio-demographic data

\begin{tabular}{|c|c|c|c|}
\hline & & \multicolumn{2}{|c|}{$\mathrm{n}=60$} \\
\hline Sno. & Parameters & Category & Number \\
\hline 1. & Age (yrs) & $\begin{array}{l}20-25 \\
26-30 \\
31-35 \\
36-40 \\
\end{array}$ & $\begin{array}{l}12(20) \\
33(55) \\
13(22) \\
2 \quad(03) \\
\end{array}$ \\
\hline 2. & Occupation & $\begin{array}{l}\text { Homemaker } \\
\text { Working }\end{array}$ & $\begin{array}{l}52(87) \\
8 \quad(13)\end{array}$ \\
\hline 3. & $\begin{array}{l}\text { Years of } \\
\text { Marriage }\end{array}$ & $\begin{array}{c}2-5 \\
6-9 \\
10-13 \\
14 \text { and Above } \\
\end{array}$ & $\begin{array}{ll}21 & (55) \\
33 & (35) \\
5 & (08) \\
1 & (02) \\
\end{array}$ \\
\hline 4. & Family Type & $\begin{array}{c}\text { Nuclear } \\
\text { Joint Family }\end{array}$ & $\begin{array}{l}35(58.4) \\
25(41.6)\end{array}$ \\
\hline 5. & $\begin{array}{l}\text { No of treatment } \\
\text { undergone }\end{array}$ & $\begin{array}{c}1 \\
2 \\
3 \\
>3 \\
\end{array}$ & $\begin{array}{c}26(43) \\
12(20) \\
14(23.3) \\
8 \quad(13.4)\end{array}$ \\
\hline 6. & No of abortions & $\begin{array}{c}\text { Nil } \\
1 \\
2 \\
>2 \\
\end{array}$ & $\begin{array}{cc}36 & (60) \\
15 & (25) \\
8 & (13.4) \\
1 & (1.6)\end{array}$ \\
\hline 7. & Education & $\begin{array}{c}\text { Illiterate } \\
\text { Primary Education } \\
\text { Higher Secondary } \\
\text { Graduate }\end{array}$ & $\begin{array}{cc}2 & (3.3) \\
6 & (10) \\
23 & (38.3) \\
29 & (48.4)\end{array}$ \\
\hline
\end{tabular}

*Figures in parenthesis indicates percenta

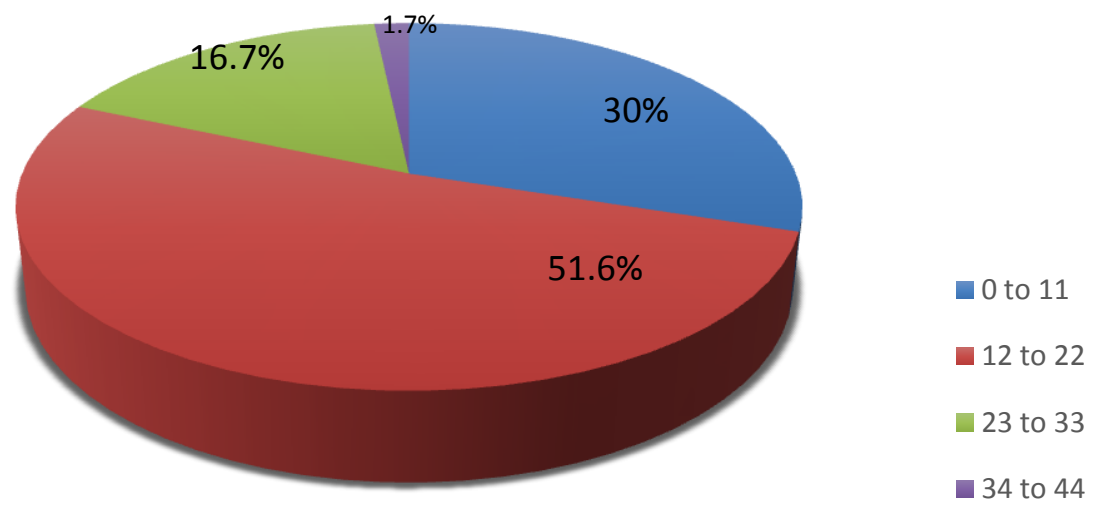

Table 4.3: Showing stress score of subjects

\begin{tabular}{|l|c|c|}
\hline S no & SCORE & STRESS LEVEL \\
\hline 1. & $0-11$ & Almost Negligible \\
\hline 2. & $12-22$ & Mild \\
\hline 3. & $23-33$ & Moderate \\
\hline 4. & $34-44$ & Severe \\
\hline
\end{tabular}




\section{Conclusion}

Stress is a part and parcel of human life. It can be both a driving force and can act as a killer in term of performance. The objective of the study was to assess the level of stress among primary infertile women undergoing IVF treatment. The study concluded that majority of the subject in the study have only mild stress level and a very few had severe stress, contributed by treatment schedule or internal conflicts and family behaviour dissension to other studies.

\section{References}

1. T Sujatha, H Shantha Mary, level of stress among women with primary infertility attending infertility clinic; India. J pharmacy and biological sciences 2016 (cited 2016 Jan-Mar)

2. Manpreet Kaur, Dr. Sukhjit Kaur, Dr. Shalini Gainder and Dr. Sandhya Ghai, stress level among primary infertile women undergoing intrauterine insemination in PGIMER India. J applied science 2016 (cited 2016 2(11)

3. Kristin L. Rooney, BA; Alice D. Domar, relationship between stress and infertility, India. J dialogues in clinical neurosciences; 2018 (cited vol 20.No.1 2018)

4. Kathy Turner, Margaret F. Reynolds-May and Lynn M. Westphal, stress and anxiety scores in first and repeat IVF Cycles, PLoS one.2013:8(5) (serial online) 2013(cited 23 may 2013)

5. J.M.J. Smeek,C M Verhaak, A.J.J.M Vingerhoets, C.G.J.S weep, J.M.W.M. Merkus, S.J. Willemsen, A.van Minnen, H Straatmam, D.D.M. Braat, stress and outcome success in IVF: the role of self reports and endocrine variables. Netherlands. J Oxford university (serial online)2005 (cited human reproduction vol 20,No 4 pp991-96,2005)
6. Galia Oron, Erica Allnutt, Tasha Lackmann, Tamar Sokal-Arnon, Hananel Holzer, Janet Takefman, using Hatha Yoga for stress reduction among women waiting for IVF treatment, Canada. Jrbmo (serial online) 2015(cited 2015.01.011) 30, 542-548

7. Arthur L. Greil, Kathleen Slauson-Blevins, and Julia McQuillan,the experience of infertility:A review of recent literature, USA, J.author manuscript (serial online) 2010

8. C.D. Lynch, R. Sundaram, J.M. Maisog, A.M. Sweeney, G M Buck Louis, preconception stress increases the risk of infertility from a couple based prospective cohort study,J Hum Reprod(serial online) 2014(cited 2014 May;29(5):1067-75

9. Lalitha K. \& Gandhi S. Stress \& Coping: BodyMind Healing. The Journal of Nursing 2005; 1:1-6

10. Domar AD., Zuttermeister PC., Friedman R. The psychological impact of infertility: a comparison with patients with other medical condition. Psychosom Obstet Gynaecol. 1993;14(suppl):45-52.

11. Fast Facts About Infertility. Available at: http://www.resolve.org/about/fast-factsabout-fertility.html. Resolve: The National Fertility Association. Accessed Sep 26, 2018. 